\title{
Practice choices of clinical associates: Policy realisation or practical reality?
}

\author{
V L Monareng, ${ }^{1}$ BSc, MB ChB, PGDip Occupational Health, Dip HIV Man (SA), MPH; J E Wolvaardt, ${ }^{1}$ BCur, MPH, PhD; \\ M Bac, ${ }^{2}$ Arts (EUR), MFamMed, MD; E M Webb, ${ }^{1}$ BSc Agric (Genetics), BSc Agric Hons, MPH, PhD \\ ${ }^{1}$ School of Health Systems and Public Health, Faculty of Health Sciences, University of Pretoria, South Africa \\ ${ }^{2}$ Department of Family Medicine, Faculty of Health Sciences, University of Pretoria, South Africa
}

Corresponding author: J E Wolvaardt (liz.wolvaardt@up.ac.za)

\begin{abstract}
Background. The Bachelor of Clinical Medical Practice (BCMP) programme was introduced in South Africa as a strategy to fill human resource gaps in both the public sector and rural communities. A previous study explored the practice intentions of BCMP students from one university prior to graduation.

Objectives. To determine whether the actual practice choices of these BCMP graduates reflect their practice intentions.

Methods. A cross-sectional analytical study invited all graduates from the four cohorts of BCMP graduates $(N=250)$ who graduated during the period 2011 - 2014 to complete an online survey. Data were exported and analysed using Stata 13. Chi-square tests of independence were done to explore associations in the data.

Results. More than $80 \%$ of participants were currently employed in the public sector, with over $50 \%$ in rural settings. Factors such as where clinical associates spent most of their lives (i.e. where they were born and raised) and bursary obligations influenced their current practice choices. There was no association between gender and rural practice choice. Intention to emigrate was not associated with origin, gender or race. Almost $90 \%$ of participants indicated an interest in furthering their studies; $46 \%$ of these intended a change in career, with $65 \%$ interested in studying medicine.

Conclusions. The practice choices of the first four cohorts of this degree were similar to their intended practice choices. Although the policy intentions of public sector employment and rural practice have been met, it is not clear what will happen once bursary obligations are fulfilled. The reasons for increased intentions to change career need further research, as a change of career would countermand gains achieved in implementing the policy.
\end{abstract}

S Afr Med J 2019;109(10):761-764. https://doi.org/10.7196/SAMJ.2019.v109i10.14052

In South Africa (SA), Bachelor of Clinical Medical Practice (BCMP) graduates, also known as clinical associates (ClinAs), form part of mid-level health workers (MLHWs). MLHWs are described as 'health cadres who have been trained for shorter periods and require lower entry education qualifications, to whom are delegated functions and tasks normally performed by more established health professionals with higher qualifications ${ }^{\prime[1]}$ MLHWs are employed to either assist healthcare professionals or render care independently, particularly in rural health centres and district hospitals, making up for a scarcity of professionals. ${ }^{[2]}$ Different countries refer to MLHWs who augment the work of doctors differently: they are called physicians' assistants in Australia and in the USA, ${ }^{[3]}$ clinical officers in Tanzania, Malawi and Kenya, and ClinAs in SA. ${ }^{[4]}$ These MLHWs undertake some of the tasks done by doctors, including examination, diagnosis and performing investigations, as well as treatment and prescribing. To foster close synergy between ClinAs and doctors, the 3-year degree course in SA is offered by three medical schools and is regulated by the Health Professions Council of South Africa. The students must also pass the national examination to ensure a uniform standard of training. ${ }^{[5]}$

The SA health system is two-tiered, comprising public and private sectors with inequitable distribution of health professionals between them. ${ }^{[6]}$ The National Department of Health is responsible for healthcare overall, with specific responsibility for the public sector. The foundation of the public sector is the primary healthcare (PHC) clinics that form the first line of healthcare access. ${ }^{[7]}$ The district health system in the nine provinces is the vehicle for the delivery of
PHC services. There are 52 health districts in SA, the boundaries of which are conterminous with municipal boundaries. ${ }^{[8]}$ Within districts, there are district hospitals, the first point of referral from PHC clinics, for more sophisticated treatment. Regional and academic hospitals provide advanced diagnostic procedures and treatments. There are nine provincial health departments that oversee the health needs of each province. ${ }^{[7]}$ This fragmented health system is further characterised by an inequitable distribution of health professionals between urban and rural areas ${ }^{[9]}$ and between the public and private sectors. ${ }^{[10]}$ The inequitable healthcare system was inherited from the apartheid era, when it was characterised by inequality in access to healthcare between different races, rural and urban areas and the public and private sectors, the number of health workers trained, and their conditions of employment. ${ }^{[11]}$ Twenty years after the end of apartheid, inequalities between rural and urban areas, private and public sectors and access to healthcare still persist. In particular, the provision of health services in rural, remote and indigenous communities remains a concern. SA has 4200 public health facilities with each PHC clinic providing care for 13718 patients (a figure that exceeds the World Health Organization's guideline of 10000 patients per clinic). ${ }^{[7]}$ The public sector has one doctor for 4219 people, compared with one doctor per 243 people in the private sector. ${ }^{[7]}$ Research cited by Rawat ${ }^{[12]}$ emphasises the unbalanced distribution between urban and rural areas, leaving SA's rural dwellers ( $44 \%$ of the total population) with only $19 \%$ of the country's doctors and $12 \%$ of its nurses. ${ }^{[12]}$ The percentage of doctors working in the private sector continues to 
rise, leaving many clinics and hospitals in the public sector without doctors. ${ }^{[10]}$

Health professionals have a choice to practise in either the public or the private sector after graduation and completing compulsory community service. In order to address the shortage of health professionals in the public sector and to promote a diversified workforce, ${ }^{[13]}$ a range of MLHWs has been created to retain skills in the public sector in general and in rural communities, with their unfavourable ratio of nurses and doctors, in particular. The creation of this cadre of health workers in SA is viewed as a country-specific, long-term system-building strategy ${ }^{[13]}$ to improve the delivery of district health services, and not just a short-term solution to health workforce shortages ${ }^{[4]}$ When training of BCMP students at the three universities began, recruitment was focused on identifying rural applicants. Students were recruited by provincial health authorities, offered bursaries, and expected to work the same number of years in return after qualifying as the duration of training. This recruitment strategy is in line with workforce development initiatives involving early activation and development of health career aspirations and intentions among young people in rural settings. It is supported by the evidence that rural background is a strong predictor of rural practice intentions and preferences. ${ }^{[14]}$

\section{Objectives}

The policy intentions (public sector employment and rural employment) and personal practice intentions of some of the cohorts from one of the three training universities are known. ${ }^{[15]}$ The present study explored the actual practice choices of these graduates and whether their personal intentions have been translated into actual practice choices, and in doing so, whether the policy intentions have been met.

\section{Methods}

A cross-sectional study of the first four cohorts of University of Pretoria (UP) BCMP graduates $(N=250)$ made use of an online Qualtrics survey. Survey questions were adapted from a previous survey. ${ }^{[15]}$ The survey was anonymous and consisted of a total of 22 closed-ended Lickert scale-type questions and 2 open-ended questions. All UP BCMP graduates who completed their degrees from 2011 to 2014 were invited to participate.

The online survey was emailed to all 250 graduates and reached 247 of them. One graduate asked to be excluded from the survey. Data were captured in Qualtrics 2015 (Qualtrics, USA) and analysed using Stata 13 (StataCorp, USA).

Analysis was done with the help of a statistician. Data were summarised with descriptive statistics, and $\chi^{2}$ analysis was done. To compare the results of our study with results from the literature, data were grouped according to categories found in the literature (urban/ rural, etc.). A $p$-value $<0.05$ was considered statistically significant.

Ethical approval for the study was granted by the Research Ethics Committee of the Faculty of Health Sciences at the University of Pretoria (ref. no. 155/2015).

\section{Results}

One hundred and thirty individuals accessed the online questionnaire and 121 consented to participate, giving a response rate of $93 \%$.

\section{Demographics of the study participants}

The mean age of the participants was 26 years (range 20 - 34), with approximately a third $(27.8 \%, 32 / 115)$ having entered the programme directly after school. The participants were mostly female and of black African origin, and most of them had lived in rural areas for much of their lives (Table 1).

\section{Current practice choices of BCMP graduates}

The majority of the study participants $(53.2 \%, 59 / 111)$ were working as ClinAs in rural areas, with $39.7 \%$ (33/111) working in urban areas. The rest indicated that they were in either non-clinical practice or research. A $\chi^{2}$ test of independence was performed to examine the relation between rural origin and rural employment. The relation between these variables was significant $\left(\chi^{2}=22.7 ; p<0.01\right)$, showing a positive association between rural origin and rural employment. There was also a positive association between urban origin and urban employment $\left(\chi^{2}=14.2 ; p<0.01\right)$. There was no association between current practice choice and gender. All ethnic groups (except black African) were combined to form a new group. This grouping was done owing to the small numbers of the other ethnic groups. There was a strong association between black African ethnic group and rural choice $\left(\chi^{2}=21.5 ; p<0.01\right)$ as well as urban choice $\left(\chi^{2}=6.6 ; p<0.01\right)$.

The largest proportion of the study participants $(36.2 \%, 54 / 149)$ were working full time in a public sector hospital (Table 2).

Approximately a fifth of the respondents $(22.1 \%, 33 / 149)$ worked part-time in the public sector, or full-time in a primary healthcare

\begin{tabular}{lll}
\multicolumn{3}{l}{ Table 1. Description of the study participants $(\mathbf{N}=\mathbf{1 2 1})$} \\
\hline Variable & Responses, $\boldsymbol{n}(\%)$ & Missing, $\mathbf{n}(\%)$ \\
\hline Age (years) & $107(88.4)$ & $14(11.6)$ \\
$20-24$ & $45(42.1)$ & \\
$25-29$ & $45(42.1)$ & \\
$30-34$ & $16(15)$ & \\
Entered directly after school & $113(93.3)$ & $8(6.7)$ \\
(by cohort graduation year) & & \\
2011 & $17(15.0)$ & \\
2012 & $38(33.7)$ & \\
2013 & $27(23.9)$ & \\
2014 & $31(27.4)$ & \\
Gender & $111(91.7)$ & $10(8.3)$ \\
Male & $41(36.3)$ & \\
Female & $70(63.1)$ & \\
Ethnicity & $112(92.6)$ & $9(7.4)$ \\
Black African & $96(85.8)$ & \\
Coloured & $2(1.8)$ \\
Indian & $1(0.9)$ & \\
White & $13(11.6)$ & \\
Area mostly lived & $110(90.9)$ & $11(9.1)$ \\
Urban & $45(40.9)$ & \\
Rural & $65(59.1)$ & \\
& & \\
\end{tabular}

\begin{tabular}{ll} 
Table 2. Current practice settings $(\mathbf{N = 1 4 9 *})$ & \\
\hline Variable & Responses, $\boldsymbol{n}$ (\%) \\
\hline Private sector with sessions in public sector & $2(1.4)$ \\
Public sector with sessions in private sector & $5(3.4)$ \\
Hospital (public sector) & $54(36.2)$ \\
Hospital (private sector) & $2(1.4)$ \\
Primary healthcare clinic (public sector) & $12(8.1)$ \\
Private GP practice & $7(4.7)$ \\
Non-governmental organisation & $13(8.7)$ \\
Medical male circumcision service & $24(16.1)$ \\
South African Military Health Service & $14(9.4)$ \\
Education/research & $8(5.4)$ \\
Non-clinical practice & $8(5.4)$ \\
*The 121 participants were asked to indicate all the practice settings that they worked in.
\end{tabular}


clinic or another government service such as the military. A few were working solely in a private general practice $(4.7 \%, 7 / 149)$, a private hospital $(1.4 \%, 2 / 149)$ or a non-governmental organisation $(8.7 \%$, $13 / 149)$. Almost $6 \%$ were no longer involved in clinical practice. Almost one-fifth $(16.1 \%, 24 / 149)$ were involved in male medical circumcision (sector not specified). The total contribution (both full time and part time) to the public sector was $58.4 \%$.

Current practice choices (all public sector options and all private sector options) were not associated with either rural or urban origin. Among the reasons for current choice of practice, the largest proportion of choices, although a minority overall, were due to bursary obligations (48.2\%, 55/114). Approximately a third of choices $(33.3 \%$, $38 / 114$ ) were due to a combination of 'other' reasons such as better remuneration, unavailability of posts and wanting a new experience, while $18.4 \%$ (21/114) cited family reasons. Seven participants did not respond to this question. The bursary obligation was less pronounced (33.3\%) between the first two groups of graduates (2011 and 2012), who were possibly no longer bound by bursary obligations. In this group ( $n=55)$, 'other' reasons $(45.5 \%)$ were the most prominent and family reasons were cited the least $(25.5 \%)$.

\section{Practice choices with no restrictions in place}

Participants were asked what their practice choice would be if they had complete freedom of choice. More than half $(57 \%, 63 / 110)$ chose rural practice. The single most preferred place of work (only 51 single responses were included) - if there were no restrictions was a district hospital $(43.1 \%, 22 / 51)$ and the least popular choice was working in a private hospital $(2.0 \%, 1 / 51)$.

Of the participants, $31.5 \%(34 / 108)$ said that they would emigrate if the degree was internationally recognised (13 participants did not answer this question). Other participants $(26.9 \%, 29 / 108)$ indicated interest in the option of gaining international experience rather than emigration, with Europe $(44.8 \%, 13 / 29)$ and the USA $(37.9 \%, 11 / 29)$ common choices. Five participants did not give a country of choice. There was no association between intention to emigrate and rural/ urban origin, gender or race.

Of the 74 participants who wanted to remain in SA, 25.7\% (19/74) indicated that they would like to continue practising as ClinAs. There was no association between those who intended to remain in the country and work as a ClinA and rural/urban origin, gender or race. While there was also no association between those who intended to stay but not work as a ClinA and rural/urban origin or race, there was a significant association between this intention and gender (female) $\left(\chi^{2}=5.1 ; p=0.02\right)$.

\section{Professional development}

An overwhelming proportion of participants (86.6\%, 97/112) intended to further their studies. Among those who responded to a follow-up question regarding choice of part-time or full-time study (92/95), most intended to study on a full-time basis $(62.0 \%, 57 / 92)$.

Of the 121 participants, $56(46.3 \%)$ intended to change their career path. The majority favoured remaining in a health-related profession, and of these $65.3 \%$ (32/49) intended to study medicine. Four participants intended to change to non-health professions such as law, business and engineering, and one did not specify their intended new profession.

There was an association between career path change and rural origin, with more study participants of rural than urban origin having intentions to change career paths $\left(\chi^{2}=4.3 ; p=0.03\right)$. An association with race was also noted $\left(\chi^{2}=7 ; p=0.07\right)$, but this was only at a $10 \%$ level of significance. No association was found between career path change and gender, race or year of graduation.

\section{Discussion}

This study explored the practice choices of the first four cohorts of ClinAs who graduated from one of the three training universities. Approximately $60 \%$ of the participants were contributing to the public sector in SA on either a full-time or part-time basis, and more than half were working in rural settings. Working in a district hospital was the most preferred setting, which is in line with the policy intention of using ClinAs at this level of the health system.

The proportion (53\%) who were working in a rural area is consistent with their practice intentions (50\%). ${ }^{[15]}$ The vast majority of participants were working as ClinAs, but a few (5.4\%) were not practising at the time of the study. This finding is consistent with their practice intentions, where $\sim 11 \%$ of the participants had no intention of working as a ClinA after graduation. ${ }^{[15]}$

The majority of the participants had lived most of their lives in rural areas. The strong association between rural origin and rural practice in this study confirms the policy decision to recruit ruralorigin candidates, which in turn is in line with international strategies to increase access to health workers in rural and remote areas. ${ }^{[9]}$ These findings also confirm that the intentions of rural practice of the first cohorts from this university were indeed met, i.e. a substantial proportion of BCMP students intended to practise in the rural areas. ${ }^{[15]}$ Furthermore, the present study confirms the finding that showed rural origin to be the single variable most associated with rural practice. ${ }^{[16]}$ Considering that most of our participants spent most of their time in rural settings, it is possible that family and community ties play a key role in influencing practice location. ${ }^{[17]}$ In the present study, however, bursary obligations played a larger role than family reasons in influencing practice choice.

The finding of rural practice being the preferred choice for most ClinAs supports a study that found that, similar to other countries, SA medical graduates of rural origin are more likely than their urban counterparts to choose rural employment. ${ }^{[18]}$ The authors also found that among these rural-origin professionals in rural practice, almost half combined private practice with sessions at a public hospital or clinic, thus contributing to public service. This phenomenon was not evident in our group, however, as most of them were in the public sector and very few combined public and private sector practice.

Bursary obligations played an important role in practice choices among the first two groups of graduates in the present study. However, as a means to retain healthcare workers in rural areas, bursary obligations are a temporary measure, as they can go back to their preferred settings after 'paying back' their time or completing community service. Bursary obligations can also discourage prospective students.

Our participants were mostly of black African descent, which may have influenced the choice of rural practice, as most ClinAs are black Africans and most of them chose rural practice. Previous studies that evaluated ethnicity and rural practice choice have, however, shown limited or no association between the two. ${ }^{[19]}$ Five studies on gender and rural practice found that rural general practitioners were more likely to be male, ${ }^{[19]}$ but in the present study no association between gender and practice choice was found.

Over the past decade, developing countries have introduced a variety of interventions to address maldistribution, recruitment and retention of healthcare workers in rural and remote areas. ${ }^{[20]}$ In SA, rural allowances, compulsory community service, bursaries and continuing medical education are some of the strategies that have been implemented in this regard. Preferential selection of students from rural areas into training programmes, salary increases and bonuses have been used in SA and developing countries, but evidence of the effectiveness of these interventions is still moderate. ${ }^{[20]}$ It is 
clear that a combination of factors needs to be considered in order to attract and retain health workers in these areas.

In the present study, the availability of posts and bursary obligations were among the reasons cited for not choosing rural practice. Many bursaries during the first 2 years of the programme came from the South African Military Health Service (SAMHS), and ClinA posts in SAMHS are only available in urban military hospitals.

If given the freedom to choose, most participants indicated that they would prefer to work in a district hospital, which could possibly be because the support and supervision provided there help to build confidence in their day-to-day work. Supportive measures receive more emphasis in countries where rural doctors are government employed than where rural healthcare is provided by private practitioners. ${ }^{[21]}$

The third of participants who said that they would emigrate if given the opportunity is a shift from the practice intention study, where $<1 \%$ stated an intention to emigrate. ${ }^{[15]}$ The reasons for intentions to emigrate were not explored and could be due to political and economic rather than professional factors.

An overwhelming proportion of participants intended to study further. This finding is not unexpected, as there was an expectation that $93 \%$ would want to study further. ${ }^{[15]} \mathrm{A}$ concern is their intention to change careers to another health science career, especially medicine. This intention of changing careers could be the result of either thwarted ambition to study medicine or the lack of a broader scope of practice for this group, and was not predicted by Doherty et al. ${ }^{[5]}$

\section{Study limitations and strengths}

The study limitations were that not all the graduates participated in the study, thus decreasing the sample size. Also, not all questions were answered by every participant. The question on medical male circumcision did not specify the sector, and this hampered the analysis of sector-related employment. The strength of this study is that it followed up a cohort of graduates whose practice intentions were known. A second strength is that the BCMP degree is only offered at three universities, so the population of all BCMP graduates is relatively small. The information from four cohorts therefore provides useful insight.

\section{Conclusions}

The practice choices of four cohorts of ClinAs were followed up and were found to be similar to their intended practice choices. Although the policy intentions of public sector employment and rural practice seem to have been met, it is not clear what will happen once the remaining bursary obligations are fulfilled. The new evidence of increased intention to change careers should concern policymakers. Further research is needed to understand the reasons for intentions to change careers, as a change of career after qualification - especially to medicine - would defeat the purpose of the introduction of this cadre of health worker.

Declaration. None.

Acknowledgements. The authors thank all the participants who gave up their time to complete the questionnaire.
Author contributions. VLM conceptualised the project and developed the protocol under the guidance of JEW and MB. VLM collected the data with the help of JEW and MB. VLM conducted the analysis with the assistance of JEW and EMW. VLM drafted the first version of the article. JEW, MB and EMW reviewed the article and made suggestions and comments. JEW adapted the article for submission to SAMJ. All authors read and agreed to the final version.

Funding. None.

Conflicts of interest. None.

1. Bluestone J. Task shifting for a strategic skill mix. IntraHealth International, Capacity Project, Technical Brief 5, June 2006. https://www.capacityproject.org/images/stories/files/techbrief_5.pdf (accessed 26 May 2019)

2. Lehmann U. Midlevel health worker: The state evidence on programmes, activities, cost and impact on outcomes: A literature review. WHO and Global Health Workforce Alliance, 2008. http://www.who. int/hrh/MLHW_review_2008.pdf (accessed 25 March 2019).

3. Miller M, Siggins I, Thomson N, Fowler G, Bradshaw S. The potential role of physician assistants in the Australian context: Final report. Health Workforce Australia, 2011. https://capa-acam.ca/wp-content/ uploads/2012/06/2012-hwa-physician-assistant-report-AU.pdf (accessed 15 March 2019).

4. Doherty I, Conco D, Couper I, Fonn S. Developing a new mid-level heath worker: Lessons learned 4. Doherty J, Conco D, Couper I, Fonn S. Developing a new mid-level heath worker: Lessons learned
from South Africás experience with clinical associates. Glob Health Action 2013;6(1):19282. https:// doi.org/10.3402/gha.v6i0.19282

5. Doherty J, Couper I, Fonn S. Will clinical associates be effective for South Africa? S Afr Med J 2012;102(11):883-835. https://doi.org/10.7196/SAMJ.5960

6. National Department of Health, South Africa. National Health Act, 2003 (Act No. 61 of 2003). National Health Insurance Policy: Towards Universal Health Coverage. Government Gazette No. 40955:627. 2017. https://www.gov.za/documents/national-health-act (accessed 1 September 2019).

7. Brand South Africa. Health care in South Africa. https://www.brandsouthafrica.com/south-africa-fastfacts/health-facts/health-care-in-south-africa (accessed 14 March 2019).

8. National Department of Health, South Africa. 2010. National Department of Health Strategic Plan 8. National Department of Health, South Africa. 2010. National Department of Health Strategic Plan
2010/2011-2012/2013. http://www.nationalplanningcycles.org/sites/default/files/country_docs/South\%20 Africa/south_africa_strategic_health_plan_2010-2013.pdf (accessed 24 March 2019).

9. World Health Organization. Increasing Access to Health Workers in Remote and Rural Areas through Improved Retention: Global Policy Recommendations. Geneva: World Health Organisation, 2010:172. https://www.who.int/hrh/retention/guidelines/en/ (accessed 1 September 2019).

10. Coovadia H, Jewkes R, Barron P, Sanders D, McIntyre D. The health and health system of South Africa: Historical roots of current public health challenges. Lancet 2009;374(9692):817-834. https://doi. org/10.1016/S0140-6736(09)60951-X

11. Heywood M. The broken thread: Primary health care, social justice and the dignity of the health worker. Health-E News, 2 September 2014. https://www.health-e.org.za/2014/09/02/paper-brokenthread-primary-health-care-social-justice-dignity-health-worker/ (accessed 5 March 2019).

12. Rawat A. Gaps and shortages in South Africa’s health workforce. Backgrounder 2012;31:1-6. https:// www.africaportal.org/publications/gaps-and-shortages-in-south-africas-health-workforce/ (accessed 2 September 2019).

13. Zhao F, Squire N, Weakliam D, et al. Investing in human resources for health: The need for a paradigm shift. Bull World Health Organ 2013;91:799-799A. https://doi.org/10.2471/blt.13.118687

14. Kumar K, Jones D, Naden, K, Roberts C. Rural and remote young people's health career decision making within a health workforce development program: A qualitative exploration. Rural Remote Health 2015;15(3303). http://www.rrh.org.au/articles/subviewnew.asp?ArticleID=3303 (accessed 2 July 018).

15. Moodley S, Wolvaardt L, Louw M, Hugo J. Practice intentions of clinical associate students at the University of Pretoria, South Africa. Rural Remote Health 2014;14:2381. www.rrh.org.au/journal/ article/2381 (accessed 5 February 2019)

16. Rabinowitz HK, Diamond JJ, Hojat M, Hazelwood CE. Rural health research: demographic, educational and economic factors related to recruitment and retention of physicians in rural Pennsylvania. J Rural Health 1999;15(2):212-218. https://doi.org/10.1111/j.1748-0361.1999.tb00742.x

17. Lindsay S. Gender differences in rural and urban practice location among mid-level health care providers. J Rural Health 2007;23(1):72-76. https://doi.org/10.1111/j.1748-0361.2006.00070.x

18. DeVries E, Reid S. Do South African rural origin medical students return to rural practice? S Afr Med J 2003;93(10):789-793

19. Laven G, Wilkinson D. Rural doctors and rural backgrounds: How strong is the evidence? A systemic review. Aust J Rural Health 2003;11(6):277-284. https://doi.org/10.1111/j.1440-1584.2003.00534.x

20. Araujo E, Maeda, A. How to recruit and retain health workers in rural and remote areas in developing countries. A guidance note. World Banks Human Development Network. Washington DC: World Bank, 2013:1-65.

21. McLean R. Continuing professional development for rural physicians: An oxymoron or just nonexistent? J Intern Med 2006;36(10):661-664. https://doi.org/10.1111/j.1445-5994.2006.01173.x 